\title{
Dynamic response enhancement of BDFIG using vector control scheme based internal model control
}

\author{
Ahsanullah Memon', Mohd Wazir Mustafa ${ }^{2}$, Shadi Khan Baloch ${ }^{3}$, Attaullah Khidrani ${ }^{4}$, \\ Touqeer Ahmed ${ }^{5}$ \\ 1,4,5 Department of Electrical Engineering, Mehran University of Engineering and Technology SZAB Campus Khairpur \\ Mirs, Pakistan \\ ${ }^{1,2}$ School of Electrical Engineering, Universiti Teknologi Malaysia (UTM), Johor Bahru, Malaysia \\ ${ }^{3}$ Department of Mechatronics Engineering, Mehran University of Engineering and Technology Jamshoro, Pakistan \\ ${ }^{4}$ Faculty of Electrical Engineering, Balochistan University of Engineering and Technology, Khuzdar, Pakistan
}

\section{Article Info}

Article history:

Received Mar 20, 2021

Revised Jun 8, 2021

Accepted Jun 15, 2021

\section{Keywords:}

BDFIG

Dynamic response

enhancement

IMC

Vector control scheme

Wind energy conversion system

\begin{abstract}
Double fed induction generator (DFIG) has shown tremendous success in wind turbines due to its flexibility and ability to regulate the active and reactive power. However, the presence of brushes and slip rings affects its reliability, stability, and power quality. Furthermore, it does not provide promising outcomes in case of faults even in presence of the crowbar circuit. In contrast, the brushless doubly fed induction generator (BDFIG) is a more reliable option for wind turbines than its mentioned counterpart due to the absence of the brushes and slip rings. This research work as such attempts to improve the dynamic performance of the vector control (VC) oriented power winding (PW) stator flux-based BDFIG by optimally selecting the proportional-integral (PI) gains through internal model control (IMC) approach. The proposed control scheme is utilized to regulate the speed, torque, and reactive power of the considered BDFIG independently. Contrary to the previous literature where the "trial and error method" is generally utilized, the current research work uses the IMC for selecting the most suitable PI parameters, thus reduces the complexity, time consumption, and uncertainty in optimal selection. The considered BDFIG based wind turbine with the proposed control scheme provides a better BDFIG control design with an enhanced dynamic response as compared to that of the same with DFIG under identical operating conditions and system configurations.
\end{abstract}

This is an open access article under the CC BY-SA license.

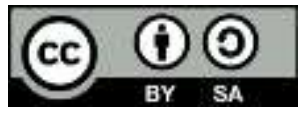

\section{Corresponding Author:}

Ahsanullah Memon

Department of Electrical Engineering

Universiti Teknologi Malaysia (UTM), Malaysia

Email: memon.ahsanullah@graduate.utm.my

\section{INTRODUCTION}

The need for electrical energy is increasing due to the rapidly increasing population and users' power demand for a good quality of life [1]. This continuous increase in power demand creates several challenges for the electric power companies such as overloading of the existing generating units, transmission lines, transformers, and feeders [2]. Furthermore, the environmental and economic impact of such power systems made them outdated for electricity generation [3]. It is for the mentioned reasons that the trend of relying on fossil fuel-based centralized power systems is declining worldwide and decentralized green energy sources such as wind, solar and sea tides are considered as potential candidates for power generation [4], [5]. Among the stated green energy options, wind energy has shown quite promising results in 
terms of reliability and efficiency [6]. However, it has been observed that the increasing power in the field of wind energy within the existing power system has introduced few new tasks in terms of grid codes for the advanced generating units, power electronic interfacing devices, and control strategies [7]. The BDFIG has excellent low voltage ride through (LVRT) handling characteristics, improved dynamic response, and most importantly, it does not contain any carbon brushes and slip rings [8]. It is worthwhile to mention here that, similar to the other wind farm machines, the speed and torque of the BDFIG needs to be regulated according to the desired operating condition through a controller with a particular control scheme.

Several control strategies have been developed for controlling BDFIG behavior. The researchers have attempted to control the BDFIG through model predictive virtual power control in [9], direct power controller (DPC) in [10], predictive torque controller by matrix converter in [11], and indirect stator quantities control in [12], however, the mentioned control schemes lags the optimal regulation of speed and reactive power with suitable dynamic response. To overcome the stated issue, the authors have utilized one of the most prominent control schemes called vector control (VC) [13], [14]. It is important to mention that the VC is generally utilized to control the machine side converter (MSC) and grid side converter (GSC) through fuzzy logic (FL) controller [15], controlled hamiltonian system [16], neural wavelet network [17], and Feedback linearization [18]. However, the difficult computations restrict the usage of these controllers into industry. One of the effective solutions of the mention problem is to use conventional PI regulator in VC as done in references [19], [20].

Owing to time constraints and complexity in conventional PI tuning approaches such as "trial and error" and Zieglar-Nichols, this research utilizes the internal model control approach to optimally tune the PI regulators; thus achieves the optimal dynamic response of the proposed BDFIG. The IMC is an analytical PI parameter selection method that considers the system parameters for compensating its open loop poles with the zeros of the PI controller, thus delivers the desired closed-loop bandwidth and time constant. Most importantly, it simplifies the control design procedure and eliminates the need for time-consuming trial-anderror step. To prove the effectiveness of the proposed method, its dynamic response is examined under different operating mechanism as such variable wind speed and reactive power change. The major contributions of this study are highlighted is being as:

a) IMC approach for obtaining optimal PI gains in VC scheme based BDFIG is comprehensively modeled and explored in order to obtain the optimal dynamic response of the machine.

b) A detailed version of the designed control scheme is made depends on several performance indicators such as speed regulation and reactive power control under different conditions.

The rest of the paper is structured as follows; Section 2 describes the operation and modeling of the machine. The converter along with the proposed IMC PI gain selection approach is discussed in Section 3. Section 4 describes the proposed VC scheme. The results are presented in Section 5. Finally, Section 6 presents the conclusion of the paper.

\section{BDFIG OPERATION AND MODELLING}

There are three modes of operation for the BDFIM machine i.e., cascaded Mode, induction Mode, and synchronous mode. Mostly, the synchronous operation of BDFIM is considered for the wind turbine which is obtained by coupling the stator windings while PW is connected with the grid, and CW is linked to the machine with the help of a power electronic converter. The active and reactive power of the machine is controlled by regulating $\mathrm{CW}$ voltage and frequency. Since the machine has two stator windings namely power winding and control winding, the number of poles for both windings must be different to avoid direct magnetic coupling [21]. The cross-coupling for PW and CW allows the control of PW current with CW supply. The relation between the number of rotors turns $\left(N_{r}\right)$, the number of poles for power winding $\left(P_{p}\right)$ and control winding $\left(P_{c}\right)$ is given in (1) and induced rotor frequencies is given in (2):

$$
\begin{aligned}
& N_{r}=P_{p}+P_{c} ; \quad P_{p} \neq P_{c} \\
& \omega_{r}=\frac{\omega_{1}+\omega_{2}}{P_{p}+P_{c}}
\end{aligned}
$$

Where $\omega_{\mathrm{r}}$ represents the rotor natural frequency, $\omega_{1}$ and $\omega_{2}$ are the natural powe winding frequencies and control winding, respectively. To design an appropriate controller for the considered grid-tied BDFIG and to evaluate and enhance the machine's dynamic performance, its mathematical model is essentially required. Since the proposed controller is aligned to the PW flux frame [22], hence; in (3) can be written as:

$$
\lambda_{p d}=\left|\lambda_{p}\right| \text { and } \lambda_{p q}=0
$$


where $\lambda_{p d}$ and $\lambda_{p q}$ denote the $\mathrm{d}$ and q components of power winding flux respectively. The voltage and flux equations for the power winding are represented as [23].

$$
\begin{aligned}
& V_{p d q}=I_{p d q} R_{p}-j \omega_{1} \lambda_{p d q}+\frac{d \lambda_{p d q}}{d t} \\
& \lambda_{p d q}=L_{p} I_{p d q}+M_{p r} I_{r d q}
\end{aligned}
$$

Where $V_{p d q}$ represents the $d$ and $q$ component of power winding voltage and $I_{p d q}$ denote the $d$ and $q$ component of power winding currents. $R_{p}, L_{p}, M_{p r}, I_{r d q}$ represents the is power winding resistance, power winding inductance, mutual inductance between the rotor and power winding, $d$ component of rotor current, and $d$ component of rotor current respectively. Similarly, the mathematical representation for the CW voltage and flux can be represented as;

$$
\begin{aligned}
& V_{c d q}=I_{c} R_{c}-j\left(\omega_{1}-N_{r} \omega_{r}\right) \lambda_{c d q}+\frac{d \lambda_{c d q}}{d t} \\
& \lambda_{c d q}=L_{c} I_{c d q}+M_{c r} I_{r d q}
\end{aligned}
$$

where $V_{c d q}$ represents the $\mathrm{d}$ and $\mathrm{q}$ component of control winding voltage, $I_{c d q}$ symbolize the $d$ and $q$ component of control winding currents, $R_{c}$ is control winding resistance, $\lambda_{c d q}$ shows $d$ and $q$ component of control winding flux respectively, $L_{c}$ is the control winding inductance, $M_{c r}$ is the mutual inductance between rotor and control winding. Finally, the RW voltage and flux can be presented mathematically as provided in (10)-(13)

$$
\begin{aligned}
& V_{r d q}=I_{r d q} R_{r}-j\left(\omega_{1}-P_{p} \omega_{r}\right) \lambda_{r d q}+\frac{d \lambda_{r d q}}{d t} \\
& \lambda_{r d q}=M_{p r} I_{p d q}+M_{c r} I_{c d q}+L_{r} I_{r d q} \\
& \lambda_{r q}=M_{p r} I_{p q}+M_{c r} I_{c q}+L_{r} I_{r q}
\end{aligned}
$$

where $V_{r d q}$ represents the $d$ and $q$ component of rotor winding voltage, $R_{r}$ is rotor winding resistance, $\lambda_{r d q}$ represents the $d$ and $q$ component of rotor winding flux respectively while $L_{r}$ denotes the rotor winding inductance. Similarly, the generated machine torque $T_{e}$ is given as following $I_{m}$ represents the magnetizing inductance:

$$
T_{e}=-\frac{3}{2} P_{p} I_{m}\left[\lambda_{p}^{*} I_{p}\right]-\frac{3}{2} P_{c} I_{m}\left[\lambda_{c}{ }^{*} I_{c}\right]
$$

\section{PROPOSED IMC BASED VC SCHEME}

A vector controller alligned on the PW reference frame is proposed to change the speed and reactive power independently [24]. The reactive power and speed are calculated analytically using the mathematical model of BDFIM while the PI controller gains are derived through the IMC method. In the vector control scheme, the dq components of PW and CW currents are regulated to obtain the desired reactive power and speed of the machine. The controlled signal obtained after conversion from DQ to ABC is fed to the PWM block which accordingly switches the inverter to inject the controlled amount of power into the grid. It is important to note that the current study utilizes only MSC to change the speed and reactive power of the machine.

\subsection{Analytical IMC model for MSI}

In this subsection, IMC method for selecting the PI regulator gains in the proposed vector control scheme is discussed in detail. The block diagram of proposed IMC based BDFIG control scheme is depicted in Figure 1. As from Figure 1 that the MSI is directly connected to the $\mathrm{CW}$ and is used to regulate the reactive power using $d$ component while active power/speed with q component of the current [25]. The frequency of the PW supply is set as $50 \mathrm{~Hz}$ throughout the simulation time. The major components of the proposed control scheme are described is being as. 


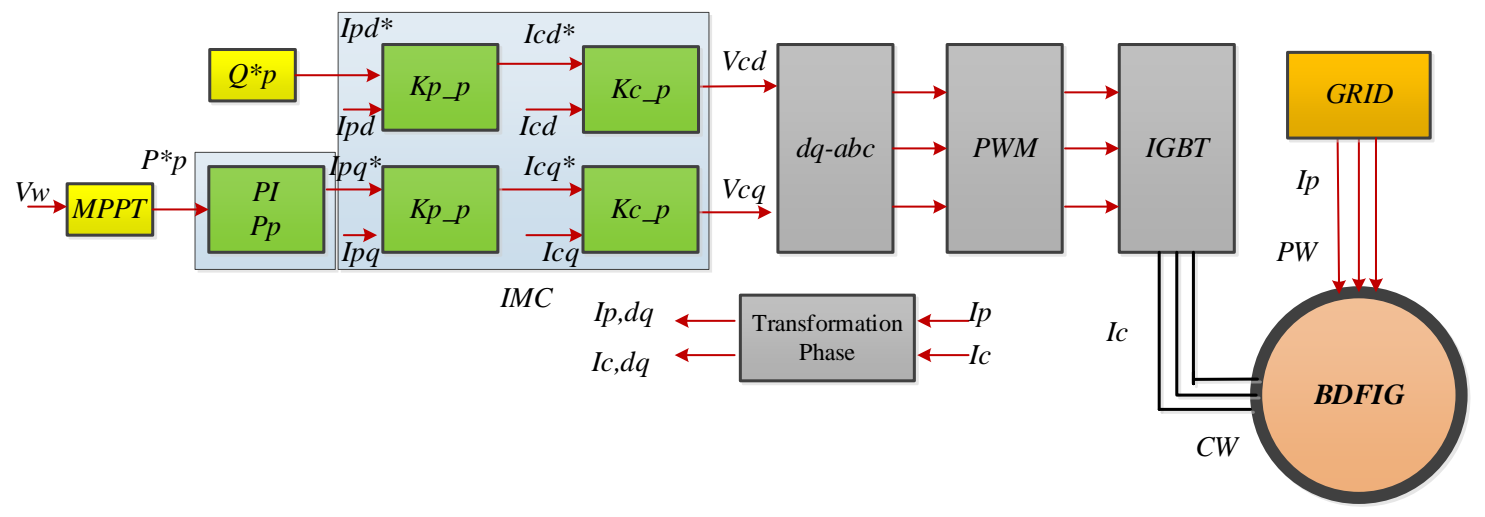

Figure 1. MSI with IMC method

\subsubsection{PW current controllers}

The PW current is regulated with the help of CW current by providing cross-coupling between two windings. The nonlinear dynamic model of the proposed grid-tied BDFIG system is represented by (12).

$$
I_{c d q}=y_{1} I_{p d q}+y_{2} \frac{d I_{p d q}}{d t}-y_{3} \lambda_{p}-y_{4} \frac{d \lambda_{p d q}}{d x}-j \omega_{1} y_{4} \lambda_{p d q}+j \omega_{1} y_{2} I_{p d q}-j \omega_{1} I_{c d q}
$$

From the above equations the direct relation between $\mathrm{PW}$ and $\mathrm{CW}$ is extracted as follows;

$$
\begin{aligned}
& I_{c}=y_{1} I_{p}+y_{2} \frac{d I_{p}}{d t} \\
& \frac{I_{p}}{I_{c}}=\frac{1}{y_{2} s+y_{1}} \quad, \quad \frac{I_{p}}{I_{c}}=\frac{1}{y_{2} s+y_{1}}
\end{aligned}
$$

To initiate the IMC based parameter extraction process, the rise time $t r_{p}$ and bandwidth $B W$ of the system is calculated as $95 \mathrm{e}^{-3}$ and 0.1841 . A vector control scheme is used to obtain high control performance of MSI whose PI regulators are tuned with the IMC method. Furthermore, the external disturbance is avoided by using feed-forward compensation. The proportional and integral gains $\left(K p_{p}\right.$ and $\left.K i_{p}\right)$ for outer loop PI regulator can be calculated by using (15).

$$
K p_{p}=2 * p i * B W_{p} * y_{2}, K i_{p}=2 * p i * B W_{p} * y_{1}
$$

\subsubsection{CW current controller}

$\mathrm{CW}$ voltage is regulated with the help of CW current as expressed in (16). The mentioned equations show the direct relationship between $\mathrm{CW}$ current and voltage in the proposed vector control scheme.

$$
v_{c d q}=d_{1} I_{c d q}+d_{2} \frac{d I_{c d q}}{d t}+\left(-d_{3}+j d_{4}\right) \lambda_{p d q}+d_{5} \frac{d \lambda_{p d q}}{d x}+\left(d_{6}+j d_{7}\right) I_{p d q}-j d_{8} I_{c d q}
$$

Similarly using the relationship between $\mathrm{CW}$ voltage and $\mathrm{CW}$ current is expressed as:

$$
v_{c}=d_{1} I_{c}+d_{2} \frac{d I_{c}}{d t} \quad, \frac{I_{c}}{v_{c}}=\frac{1}{d_{2} s+d_{1}}
$$

The expressions for calculating $K p_{c}$ and $K i_{c}$ values for the CW current control through the IMC method are provided in (18):

$$
K p_{c}=2 * p i * B W_{c} * d_{2} \quad, K i_{c}=2 * p i * B W_{c} * d_{1}
$$

\subsubsection{Speed control design}

Since the PW voltage is taken as reference, therefore the d component of PW flux remains constant. The generated torque for the machine can be calculated as:

$$
T_{e}=-\frac{3}{2}\left(\mathrm{P}_{\mathrm{p}}+\mathrm{P}_{\mathrm{c}}\right)\left|\lambda_{p}\right| I_{p q}
$$


The transfer function model for in-terms of the speed is given by:

$$
\frac{w r}{w r *}=\frac{\frac{3}{2} \mathrm{P}_{\mathrm{p}}\left|\lambda_{p}\right| K i_{\omega_{\mathrm{r}}}}{s^{2}+\left[\frac{B}{J}+\frac{3}{2} \mathrm{P}_{\mathrm{p}}\left|\lambda_{p}\right| K p_{\omega_{\mathrm{r}}}\right] s+\frac{3}{2} \mathrm{P}_{\mathrm{p}}\left|\lambda_{p}\right| K i_{\omega_{\mathrm{r}}}}
$$

Thus, from the above equations, the value for the $K p \omega$ and $k i \omega$ is obtained as provided in (21):

$$
K p_{\omega_{\mathrm{r}}}=\left(2 \omega n * \frac{J}{6}\right), K i_{\omega_{\mathrm{r}}}=\left(\omega n^{2} * \frac{J}{6}\right)
$$

The reactive power is regulated with the q component of current in the vector control method of BDFIG in the current study while the power winding flux $\lambda \mathrm{p}$ is held constant throughout the simulation run. It is important to note that the reactive power regulation is necessary for injecting the controlled amount of reactive power to the grid during fault conditions to avoid disconnection of the machine from the rest of the network [26].

\section{RESULTS AND DISCUSSION}

To regulate the speed and reactive power of the proposed BDFIG through the proposed control strategy, a simulation model is developed in MATLAB/SIMULINK version 2018b as shown in Figure 2 and the parameters of machine are listed in Table 1. Based on the objective of the study, the simulated outcomes from the proposed control strategy are divided into two broad categories as discussed below.

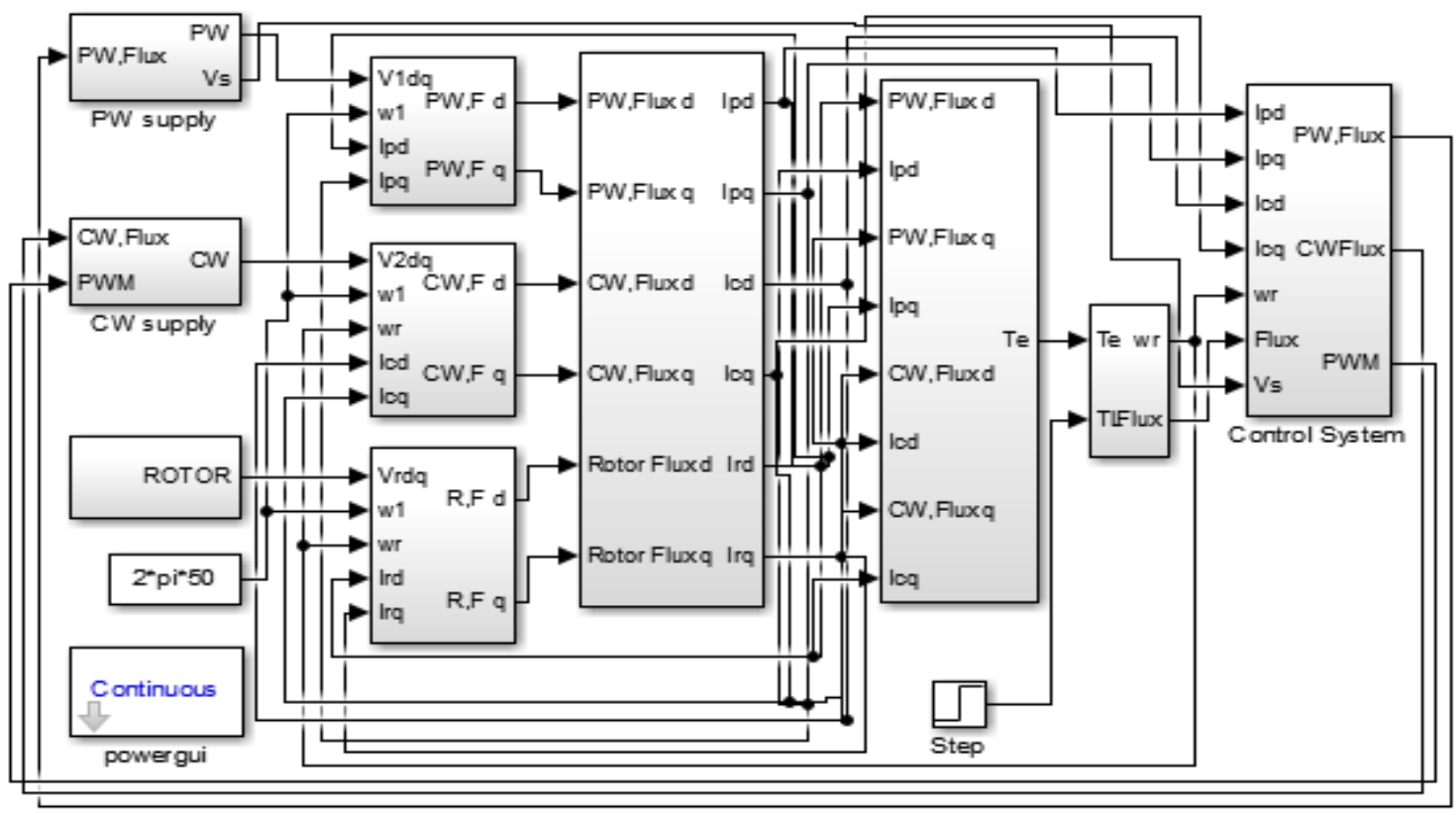

Figure 2. Simulink model for BDFIG with the control scheme

Table 1. The BDFIG parameters

\begin{tabular}{llll}
\hline \multicolumn{1}{c}{ Parameters } & \multicolumn{1}{c}{ Value } & \multicolumn{1}{c}{ Machine Parameters } & \multicolumn{1}{c}{ Parameters } \\
\hline PW pole pairs(pp) & 2 & Power Winding Resistance (Rsp) & $2.3 \mathrm{ohm}$ \\
CW pole pairs pc & 4 & Control Winding Resistance (Rsc) & 4 \\
PW (Voltage) & $240 \mathrm{~V}$ & Rotor Winding Resistance (Rr) & $1.2967 \mathrm{e}-4 \mathrm{ohm}$ \\
CW (Voltage) & $240 \mathrm{~V}$ & Self-Inductance of PW (Lsp) & $0.3498 \mathrm{H}$ \\
& & & \\
PW (Current) & $8 \mathrm{~A}$ & Self-Inductance of CW (Lsc) & $0.3637 \mathrm{H}$ \\
CW (Current) & $8 \mathrm{~A}$ & Self-Inductance of RW (Lr) & $4.4521 \mathrm{e}-5 \mathrm{H}$ \\
Rated Torque & $100 \mathrm{Nm}$ & Mutual Inductance between PW and RW (Lhp) & $0.0031 \mathrm{H}$ \\
Grid frequency(Hz) fp & 50 & Mutual Inductance between CW and RW(Lhc) & $0.0022 \mathrm{H}$ \\
Synchronous speed & $52 \mathrm{radians} / \mathrm{sec}$ & Rotor Moment of Inertia (J) & $0.4 \mathrm{~kg} . \mathrm{m} 2$ \\
\hline
\end{tabular}




\subsection{Case 1: speed regulation}

Control of the rotor speed is very crucial in the application of wind turbines where the wind speed is unpredictable. Therefore, in this case, the speed of the machine is regulated between 0 to $70 \mathrm{rad} / \mathrm{s}$ at the constant torque of $0 \mathrm{~N} . \mathrm{m}$ and the reactive power of 500 VAR. The simulation is perfomed to see the impact of changing speed on PW, CW, and reactive power. The corresponding response of the system is depicted in Figure 3(a) while its impact on the CW current, PW current, and reactive power is shown in Figures 3(b)-(d) respectively.

As can be seen from the mentioned figures that the machine shows good dynamic response and tracks the speed changes effectively. The controller is able to regulate the speed in a wide range of $\pm 30 \%$ of 52 radians/sec; thus, maintains the stable operation of the system. The PW, CW currents and reactive power follows the changes effectively withoutany noticeable overshoots. It is important to note that, when the speed of the BDFIM is changed from sub-natural to super-natural speed, the CW currents varry their sequence to uphold synchronous operation as evident from Figure 3(b). The synchronous speed of the machine is $52 \mathrm{rad} / \mathrm{sec}$ in this paper.

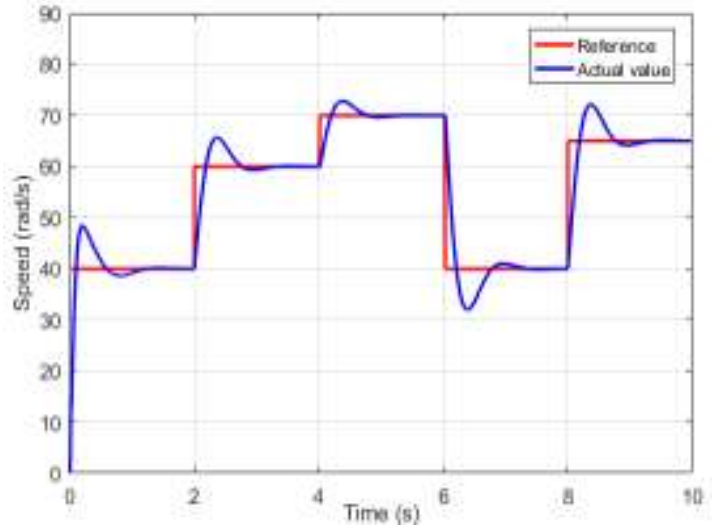

(a)

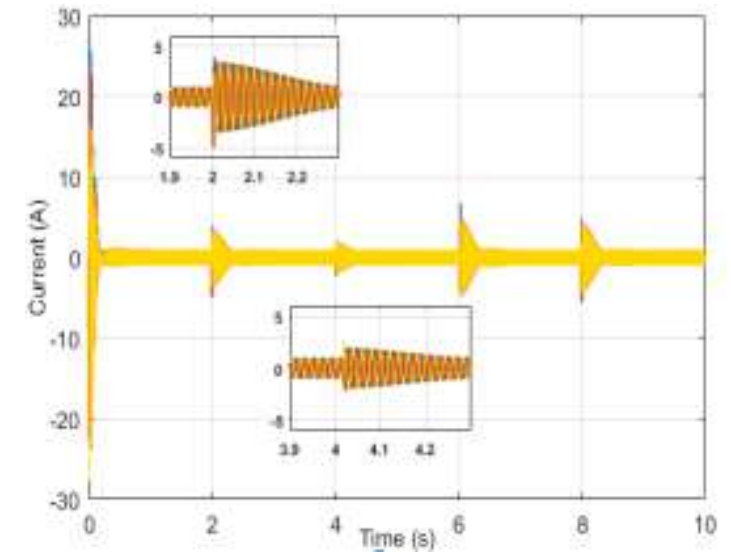

(c)

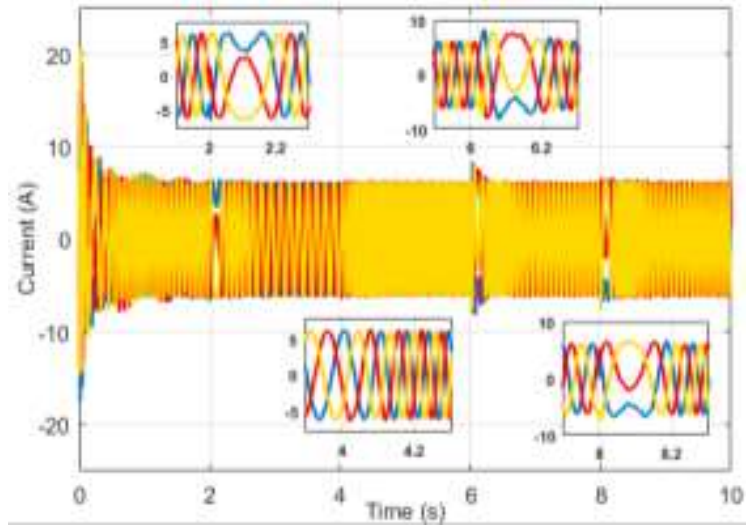

(b)

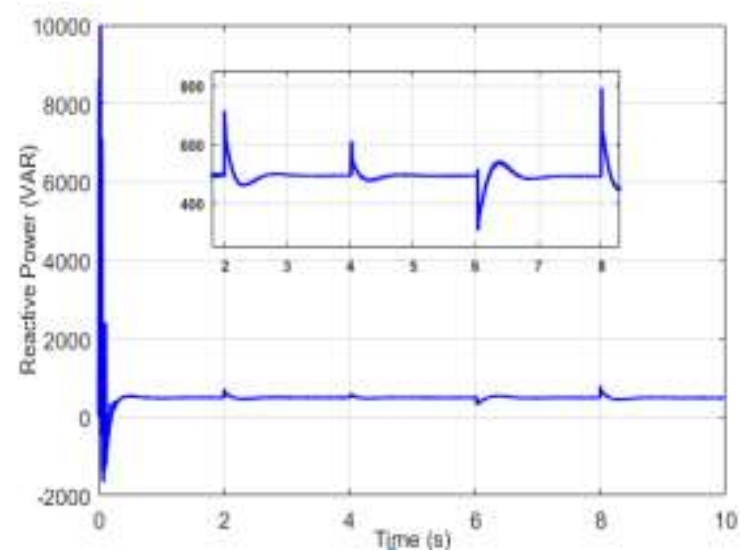

(d)

Figure 3. These figures are; (a) speed regulation, (b) control winding current, (c) power winding current, (d) reactive power

\subsection{Case 2: reactive power control}

In this case, the effect of changes in reactive power on system stability is examined. Step changes in the reactive power of the machine are made at $0,2,4,6$, and 8 seconds of the simulation run as depicted in Figure 4(a). The corresponding impact of such sharp changes in reactive power, speed, PW current, and CW current is depicted in Figures 4(b)-(d) respectively.

It can be observed from Figure 4 that the changes in reactive power affect the speed, PW current, and $\mathrm{CW}$ current, however, the proposed control scheme effectively manages to maintain the stable operation of the machine with a suitable dynamic response. The Figure 4 show that the proposed IMC based vector control scheme is able to track the changes in the reactive power, thus making the BDFIG supply the required reactive power to the grid during the normal and fault conditions. 


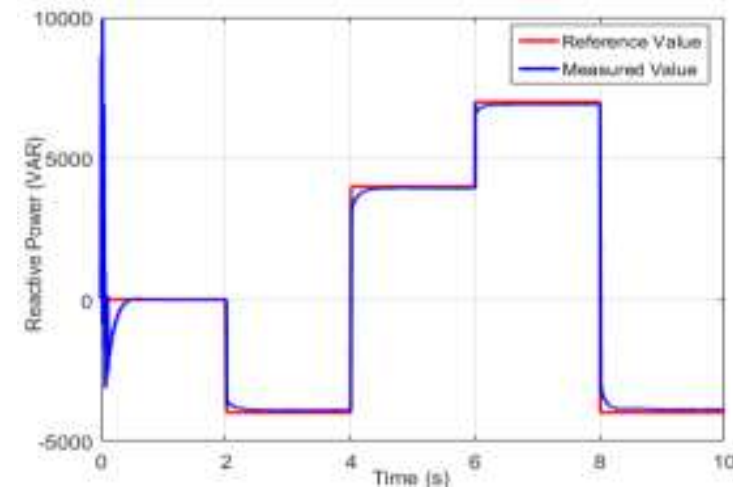

(a)

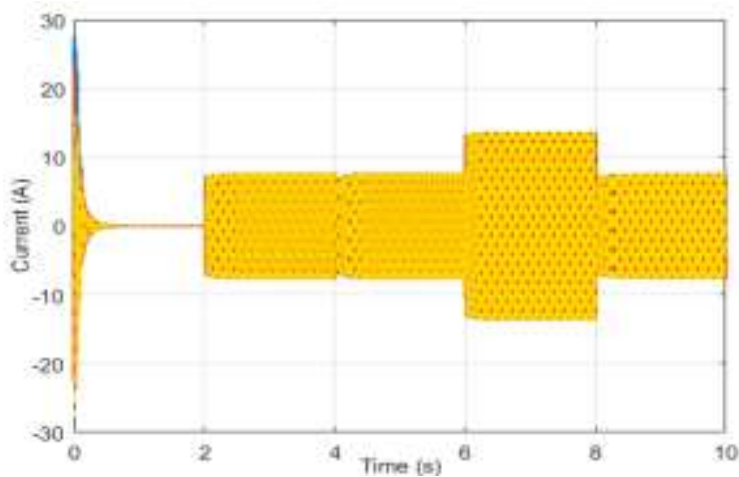

(c)

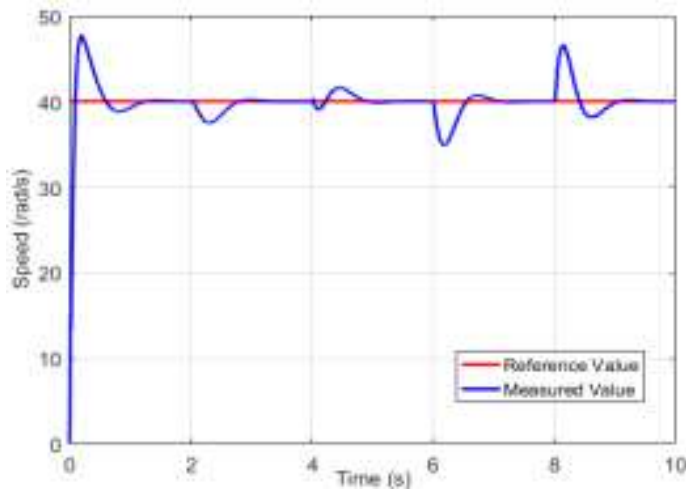

(b)

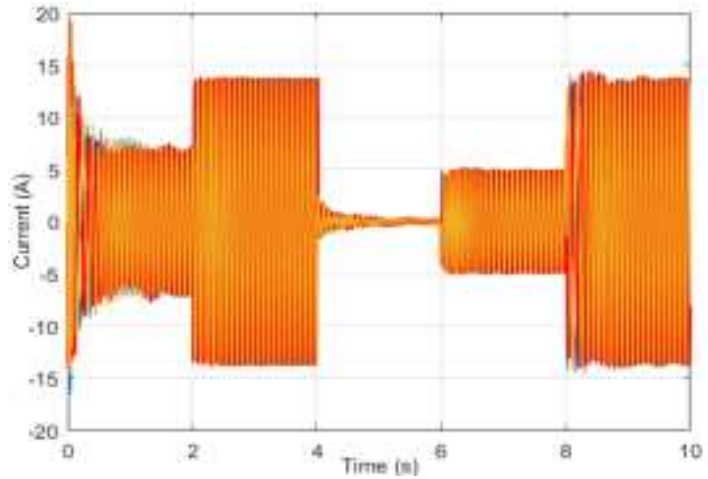

(d)

Figure 4. These figures are; (a) reactive power, (b) speed regulator, (c) power winding current, (d) control winding current

\section{CONCLUSION}

This paper presented an IMC based vector control scheme for BDFIM. The proposed control scheme can regulate the speed and reactive power of the BDFIG effectively with a suitable dynamic response. To enhance the transient response of the system during normal operating conditions, the gains of the PI regulators are selected using the IMC method. To validate the effectiveness of the proposed control scheme, its performance is evaluated under sharp variations in different system control parameters such as speed, torque, and reactive power. The proposed control scheme tracks the changes in the mentioned variables accurately with excellent dynamic response and maintains the stable operation of the system; thus, proves the effectiveness of the proposed control scheme.

\section{REFERENCES}

[1] M. Fatima Zohra, B. Mokhtar, and M. Benyounes, "Sliding mode performance control applied to a DFIG system for a wind energy production," International Journal of Electrical and Computer Engineering (IJECE), vol. 10, no. 6, pp. 6139-6152, 2020, doi: 10.11591/ijece.v10i6.pp6139-6152.

[2] T. Jumani, M. Mustafa, M. Rasid, N. Mirjat, M. Baloch, and S. Salisu, "Optimal Power Flow Controller for GridConnected Microgrids using Grasshopper Optimization Algorithm,” Electronics, vol. 8, no. 1, p. 111, Jan. 2019, doi: 10.3390/electronics8010111.

[3] T. A. Jumani, et al., "Computational intelligence-based optimization methods for power quality and dynamic response enhancement of ac microgrids," Energies, vol. 13, no. 15, p. 4063, Aug. 2020, doi: 10.3390/en13164063.

[4] T. A. Jumani, M. W. Mustafa, M. M. Rasid, N. H. Mirjat, Z. H. Leghari, and M. Salman Saeed., "Optimal voltage and frequency control of an islanded microgrid using grasshopper optimization algorithm," Energies, vol. 11, no. 11, 2018, doi: 10.3390/en11113191.

[5] T. A. Jumani, M. W. Mustafa, A. S. Alghamdi, M. M. Rasid, A. Alamgir, and A. B. Awan, "Swarm IntelligenceBased Optimization Techniques for Dynamic Response and Power Quality Enhancement of AC Microgrids: A Comprehensive Review," IEEE Access, vol. 8, pp. 75986-76001, 2020, doi: 10.1109/ACCESS.2020.2989133.

[6] M. Hussain, M. H. Baloch, A. H. Memon, and N. K. Pathan, "Maximum Power Tracking System Based on Power Electronic Topology for Wind Energy Conversion System Applications," Engineering, Technology \& Applied Science Research, vol. 8, no. 5, pp. 3392-3397, Oct. 2018, doi: 10.48084/etasr.2251. 
[7] M. H. Baloch, D. Ishak, S. T. Chaudary, B. Ali, A. A. Memon, and T. A. Jumani, "Wind power integration: An experimental investigation for powering local communities," Energies, vol. 12, no. 4, 2019, doi: 10.3390/en12040621.

[8] T. D. Strous, H. Polinder, and J. A. Ferreira, "Brushless doubly-fed induction machines for wind turbines: developments and research challenges," IET Electric Power Applications, vol. 11, no. 6, pp. 991-1000, 2016, doi: 10.1049/iet-epa.2016.0118.

[9] X. Wei, M. Cheng, R. Luo, L. Xu, and J. Zhu, "Model predictive virtual power control of brushless doubly-fed induction generator for fast and smooth grid synchronisation," IET Renew. Power Gener., vol. 13, no. 16, pp. 30803087, Dec. 2019, doi: 10.1049/iet-rpg.2019.0566.

[10] A. Rahab, F. Senani, H. Benalla, and R. Abderezzak, "Direct Power Control of Brushless Doubly-fed Induction Generator Used in Wind Energy Conversion System," International Journal of Power Electronics and Drive Systems (IJEPDS), vol. 8, no. 1, pp. 417-433, 2017, doi: 10.11591/ijpeds.v8.i1.pp417-433.

[11] Bayhan, S., Kakosimos, P., and Rivera, M., "Predictive torque control of brushless doubly fed induction generator fed by a matrix converter," 2018 IEEE 12th International Conference on Compatibility, Power Electronics and Power Engineering (CPE-POWERENG 2018), 2021, pp. 1-6, doi: 10.1109/CPE.2018.8372497.

[12] R. Zhao, A. Zhang, Y. Ma, X. Wang, J. Yan, and Z. Ma, "The Dynamic Control of Reactive Power for the Brushless Doubly Fed Induction Machine With Indirect Stator-Quantities Control Scheme," IEEE Transactions on Power Electronics, vol. 30, no. 9, pp. 5046-5057, 2015, doi: 10.1109/TPEL.2014.2365675.

[13] P. E. Troncoso, R. J. Mantz, and P. E. Battaiotto, "Active and reactive power regulation in wind turbines based on BDFIG machines,” 2017 IEEE URUCON, vol. 2017, pp. 1-4, 2017, doi: 10.1109/URUCON.2017.8171845.

[14] J. Chen, W. Zhang, B. Chen, and Y. Ma, "Improved vector control of brushless doubly fed induction generator under unbalanced grid conditions for offshore wind power generation," IEEE Transactions on Energy Conversion, vol. 31, no. 1, pp. 293-302, Mar. 2016, doi: 10.1109/TEC.2015.2479859.

[15] Beddar, A., Bouzekri, H., Babes, B., and Afghoul, H., "Experimental enhancement of fuzzy fractional order PI+ I controller of grid connected variable speed wind energy conversion system," Energy Conversion and Management, pp. 569-580, 2016, doi: 10.1016/j.enconman.2016.06.070.

[16] Y. Gui, C. Kim, and C. C. Chung, "Improved low-voltage ride through capability for PMSG wind turbine based on port-controlled hamiltonian system," International Journal of Control, Automation and Systems, vol. 14, no. 5, pp. 1195-1204, Oct. 2016, doi: 10.1007/s12555-014-0480-y.

[17] Alizadeh, M., and Kojori, S. S., "Augmenting effectiveness of control loops of a PMSG (permanent magnet synchronous generator) based wind energy conversion system by a virtually adaptive PI (proportional integral) controller," Energy, vol. 91, pp. 610-629, 2019, doi: 10.1016/j.energy.2015.08.047.

[18] Errami, Y., Ouassaid, M., and Maaroufi, M., "A performance comparison of a nonlinear and a linear control for grid connected PMSG wind energy conversion system," International Journal of Electrical Power \& Energy Systems, vol. 68, pp. 180-194, 2015, doi: 10.1016/j.ijepes.2014.12.027.

[19] M. G. Hussien, W. Xu, and Y. Liu, "Vector Control Schemes for Direct Voltage Control of the Stand-Alone Brushless Doubly-Fed Induction Generator," 2018 21st International Conference on Electrical Machines and Systems (ICEMS), 2018, pp. 1307-1312, doi: 10.23919/ICEMS.2018.8549244.

[20] K. Ji, W. Long, and J. He, "Indirect Vector Control for Stand-alone Operation Brushless Doubly Fed Induction Generator Employing Power Winding Stator Flux Orientated Approach," IOP Conference Series: Materials Science and Engineering, Oct. 2019, vol. 612, no. 4, p. 042085, doi:10.1088/1757-899X/612/4/042085.

[21] F. Zhang, S. Yu, Y. Wang, S. Jin, and M. G. Jovanovic, "Design and Performance Comparisons of Brushless Doubly Fed Generators with Different Rotor Structures," IEEE Transactions on Industrial Electronics, vol. 66, no. 1, pp. 631-640, 2018, doi: 10.1109/TIE.2018.2811379.

[22] A. Zhang et al., "Crowbarless Symmetrical Low-Voltage Ride through Based on Flux Linkage Tracking for Brushless Doubly Fed Induction Generators," IEEE Transactions on Industrial Electronics, vol. 67, no. 9, pp. 7606-7616, Sep. 2020, doi: 10.1109/TIE.2019.2944096.

[23] M. N. F. Nashed, M. N. Eskander, and M. A. Saleh, "Mitigation of faults in grid-connected wind-driven single machine brushless double-fed induction generator," Indonesian Journal of Electrical Engineering and Computer Science (IJEECS), vol. 15, no. 3, pp. 1178-1188, 2019, doi: 10.11591/ijeecs.v15.i3.pp1178-1188.

[24] G. Joshi and P. Pius, "ANFIS controller for vector control of three phase induction motor," Indonesian Journal of Electrical Engineering and Computer Science (IJEECS), vol. 19, no. 3, pp. 1177-1185, 2020, doi: 10.11591/ijeecs.v19.i3.pp1177-1185.

[25] S. L. S. Louarem, D. E. C. Belkhiat, T. Bouktir, and S. Belkhiat, "An Efficient Active and Reactive Power Control of DFIG for a Wind Power Generator," Engineering, Technology \& Applied Science Research, vol. 9, no. 5, pp. 4775-4782, Oct. 2019, doi: 10.48084/etasr.3007.

[26] P. D. Chung, "Evaluation of Reactive Power Support Capability of Wind Turbines," Engineering, Technology \& Applied Science Research, vol. 10, no. 1, pp. 5211-5216, Feb. 2020, doi: 10.48084/etasr.3260. 